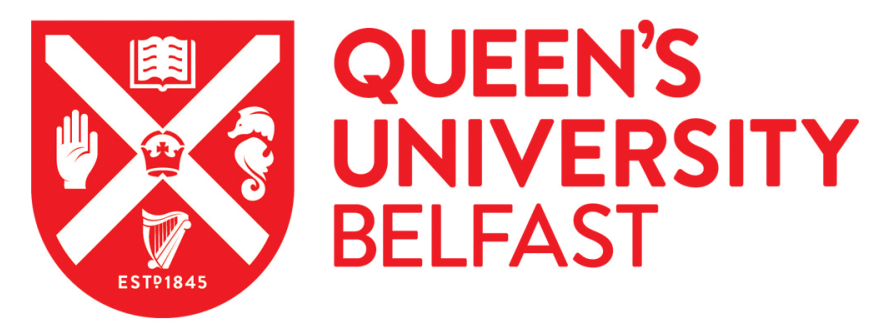

\title{
The Characterization of Friction Stir Welding Process Effects on Stiffened Panel Buckling Performance
}

Murphy, A., McCune, W., Quinn, D., \& Price, M. (2007). The Characterization of Friction Stir Welding Process Effects on Stiffened Panel Buckling Performance. Thin-Walled Structures, 45(3)(3), 339-351.

https://doi.org/10.1016/j.tws.2007.02.007

\section{Published in:}

Thin-Walled Structures

Document Version:

Peer reviewed version

Queen's University Belfast - Research Portal:

Link to publication record in Queen's University Belfast Research Portal

\section{General rights}

Copyright for the publications made accessible via the Queen's University Belfast Research Portal is retained by the author(s) and / or other copyright owners and it is a condition of accessing these publications that users recognise and abide by the legal requirements associated with these rights.

Take down policy

The Research Portal is Queen's institutional repository that provides access to Queen's research output. Every effort has been made to ensure that content in the Research Portal does not infringe any person's rights, or applicable UK laws. If you discover content in the Research Portal that you believe breaches copyright or violates any law, please contact openaccess@qub.ac.uk. 


\title{
The Characterisation of Friction Stir Welding Process
}

\section{Effects on Stiffened Panel Buckling Performance}

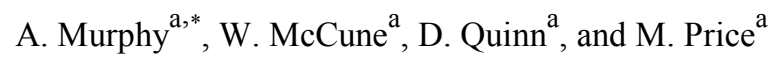 \\ a School of Mechanical and Aerospace Engineering, Queen's University Belfast, \\ Ashby Building, Belfast. N. Ireland, U.K. BT9 5AH
}

The introduction of advanced welding methods as an alternative joining process to riveting in the manufacture of primary aircraft structure has the potential to realise reductions in both manufacturing costs and structural weight. However, welding processes can introduce undesirable residual stresses and distortions in the final fabricated components, as well as localised loss of mechanical properties at the weld joints. The aim of this research is to determine and characterise the key process effects of friction stir welding assembly methods on stiffened panel static strength performance. Utilising experimentally validated Finite Element modelling methods, it is demonstrated that welding induced residual stresses have a significant influence, and that collapse behaviour is less sensitive to advanced process effects and process effect magnitudes than panel initial buckling behaviour.

\section{Keywords}

Friction stir welding, initial imperfections, welding residual stress, buckling analysis, post-buckling analysis.

\section{Introduction}

The aerospace industry has a strong focus on reducing design, manufacture, operation and maintenance costs. This focus on cost has resulted in the emergence of manufacturing processes, such as welding, being applied to the fabrication of aerospace primary structure. In Europe, Airbus has applied laser beam welding to the fabrication of fuselage and pressure bulkhead skin-stiffener panels, implementing welding for a limited design range on the A318 and A380 ${ }^{1}$. In North America, Eclipse Aviation has developed the Eclipse 500 business jet, utilising friction stir welding in both wing and fuselage skin-stiffener-frame

\footnotetext{
* Corresponding author. Tel.: +44 (0)28 9097 4095; fax: +44 (0)28 90975576.
}

E-mail address: a.murphy@qub.ac.uk (A. Murphy). 
fabrication ${ }^{2}$. Expansion beyond these current applications has associated risks due to limited generic strength data. A major restriction for fully optimised implementation of these advanced processes to full manufacture of aircraft structures is the lack of fundamental knowledge on the linkages between welding process parameters and the resultant induced or modified panel properties, and the consequence of these welding process effects on strength performance of the fabricated structure.

Significant thermal behaviour, elastic- and plastic-deformation and metallurgical property changes occur simultaneously in the proposed welding techniques. Methods for strength analysis and design are currently under development ${ }^{3-6}$, as well as manufacturing process parameter optimisation for reliable welds. Current strength analysis methods apply empirically determined knock down factors which account for all welding effects. This approach is permitting the introduction of welding to aircraft stiffened panel assembly, but is limited as direct links between welding process effects, such as locally modified material properties, and buckling strength are hidden within these knockdown factors. As a result of the incomplete knowledge, uncertainties remain in analysis procedures for strength performance.

The aim of this research is to determine and characterise the key process effects of advanced welding assembly methods on stiffened panel static strength performance. This in-depth understanding of the relationships between welding process effects and buckling and collapse strength is required to achieve manufacturing cost reductions without introducing structural analysis uncertainties and hence conservative over designed welded panels.

The presented work is part of a larger research program which has a building block approach, examining in order, coupons, structural detail, sub-components and full scale panels. Previous structural detail level research ${ }^{7}$ investigated the key friction stir welding process effects on stiffened panel crippling performance. This current work is focused at the sub-component level and examines multi stiffener panels. The objective is the expansion of the current knowledge, developed at the structural detail level, on the linking relationships between welding process effects and stiffened panel buckling performance, to the sub-component level.

Considering the number and range of potential welding process effects which may relate to buckling and collapse strength performance, the development of full empirical relationships would not be cost effective. Therefore a series of experimental tests are undertaken on sub-component specimens with known welding process parameters and measured welding process effects. The generated experimental data is then used to validate a non-linear Finite Element modelling methodology considering initial skin buckling and post buckling failure behaviour. Applying statistical methods along with the validated 
simulation procedures, a range of welding process effects are studied to identify the dominant welding effects and the influence of these welding effects on strength performance.

Toward this aim the following section reviews the state of the art associated with aerospace friction stir welding, setting into perspective the present study. This is followed by details on the design, manufacture and experimental testing of the welded sub-component specimens used in the validation of the computational simulation procedures. Validation results are presented before the simulation methods are used along with statistical methods to map the welding process effects. The welding process effects versus static strength performance results are then outlined and discussed before the paper is concluded with a summary of the experimental and computational findings.

\section{Current Aerospace State-of-the-Art}

Friction stir welding is a solid-state joining process which has the potential for superior mechanical properties, lower residual stresses and distortions. These advantages are primary due to lower processing temperatures when compared with traditional fusion welding processes. Early successes have resulted in the technology diffusion outpacing the fundamental understanding of key elements of the process, with current applications in the aerospace, land and marine transport industries. To date, designs have been developed based on bespoke experimental data and generic design and analysis rules and tools are missing.

Lockheed-Martin Space Systems along with NASA's Langley Research Centre investigated friction stir welding as a potential replacement for the riveted sheet-stiffener panel construction of launch vehicle dry bay structures. The work examined the static strength of single-stiffener crippling specimens ${ }^{4}$. The research considered aluminium lithium (2090-T83) specimens with stiffeners of a hat-section profile. The physical tests considered identical single-stiffener specimens fabricated using conventional riveting and lap welding. Results indicated that the welded design exhibited a higher initial buckling load, but a lower crippling failure load than the riveted design. No special analysis techniques or material properties were used in the welded specimen analysis to account for welding effects. In preceding work, Murphy et al ${ }^{7}$, an attempt was made to address this limitation by considering welding process effects in the strength analysis. Again, the work examined crippling collapse of welded single skin-stiffener specimens. This was achieved by undertaking coupled experimental and computational studies. Results demonstrated that initial skin buckling was principally influenced by the magnitude of the welding induced residual stresses and the resultant geometric distortions. Initial skin buckling performance decreased continuously with higher magnitudes of initial residual stress. Considering crippling collapse, the material strength within 
the Heat Affected Zone (HAZ) and the welding induced residual stresses were found to have the most significant influence.

Only stiffeners with low slenderness ratios are likely to fail with complete section crippling. External panels within a civil aircraft wing or fuselage will have intermediate slenderness ratios and failure modes are characterised by combined interaction between global flexure and local cross-sectional buckling modes. The foregoing crippling analysis ${ }^{4,7}$ permitted testing of weld joints to very high stress levels, greater than for specimens with intermediate slenderness ratios. However the analysis only considered specimens with a single weld and associated weld effects. In addition, the percentage of specimen crosssectional area classed as welding process affected, that is to say the thermo-mechanically affected zone (including weld nugget region) and heat affected zone, is much greater than would be found on an multi stiffener fuselage or wing panel. Therefore findings from single stiffener structural detail investigations are not necessarily valid for multi stiffener panels.

The combined Lockheed-Martin NASA program extended the structural detail work to multi stiffener compression specimens ${ }^{5}$. Both welded and riveted large-scale multi stiffener panel specimens were designed, manufactured and experimentally tested. Both the riveted and welded specimens exhibited large initial geometric imperfections and initial sheet buckling well below the predicted values. Pre-buckling global stiffness of both panels was approximately equal; however the welded panel exhibited a lower post-buckling stiffness and a $20 \%$ lower failure load than the riveted panel. The aim of the work herein, to account for welding effects in the structural analysis of multi stiffener panels, will allow understanding of any potential performance gap between riveted and welded designs and therefore potential treatments.

\section{Experimental Validation}

\section{A. Sub-Component specimen design and experimental analysis}

The analysis work to assess the significance of welding process effects on performance is to be based and therefore validated on multi stiffener panels. The design philosophy of the welded panels is the same as for riveted panels, with initial skin buckling occurring at a percentage of the ultimate load, and subsequent post-buckling failure due to buckling collapse of the stiffeners. Within the post-buckling range as with riveted designs the stiffener plus an effective width of skin ${ }^{8}$ is assumed to act as a column, independent of the buckled skin. No weld joint failure should occur before the ultimate collapse load; this is similar in design philosophy to removing the potential for inter rivet buckling in a riveted panel design. 
The sub-component specimen is representative of panel structure found on the lower fuselage belly of a mid-sized commercial transport aircraft. The design of panel structure within this region is typically static compression critical. A number of initial configurations were studied and a general test specimen layout defined with friction stir welded Z-section longitudinal stiffeners (7075-T76511 extrusion), and a flat skin base (2024-T3), with a flat specimen selected for ease of manufacture and test. Fig. 1 details the specimen configuration with Table 1 presenting the stiffener cross-sectional dimensions. The specimen central stiffener was designed to have a lower failure stress than the edge stiffeners to ensure that specimen failure is initiated at the specimen centre. As the specimens are designed to represent fuselage structure local pad-ups are designed at each skin-stiffener interface. This design feature is aimed at improving fatigue performance by reducing cycle hoop loading due to pressurisation across the skinstiffener weld joins. To produce the pad-ups a sheet of equal thickness to the specimen skin plus pad-up was selected and the areas between pad-ups then pocketed out by mechanical milling before stiffeners were welded on. The specimen stiffener extrusions were heat treated to a T76511 temper before being welded to the pocketed T3 temper skin material. Three specimens were manufactured and labelled as FSW-SSC-1, FSW-SSC-2 and FSW-SSC-3. No post-welding heat treatment process was carried out on the specimens, and a minimum period of time was permitted to elapse between specimen welding and specimen testing to ensure a stable state of natural ageing.

When examining the stability performance of welded thin-walled panels, six forms of imperfection may be considered:

(a) Plate out-of-plane deflection between stiffeners in terms of pattern and magnitude,

(b) Stiffener longitudinal (column type) out-of-plane deflections in terms of pattern and magnitude,

(c) Stiffener lateral out-of-plane deflections in terms of pattern and magnitude,

(d) Welding induced residual stress in plate elements in terms of tensile residual stress magnitude, tensile residual stress breadth and compressive residual stress magnitude,

(e) Welding residual stress in stiffeners in terms of tensile residual stress magnitude/breadth and compressive residual stress magnitude,

(f) The material Heat Affected Zone in terms of its width and the level of material strength degradation. Within this study only imperfection (c) is not measured or computationally modelled as preliminary measurements determined the magnitude of stiffener lateral out-of-plane deflections as very small.

Once welded, each specimen underwent a skin surface scan to measure the initial skin out-of-plane geometric distortion. Each specimen exhibited the same general geometric imperfection with a half sine 
wave along the length of the specimen in the stiffener direction and lateral to the stiffener direction a smaller half sine wave. Analysing the magnitude of the curvature parallel to stiffener weld lines the maximum out-of-plane magnitude is $120 \%$ the skin thickness measured from the specimen edge to specimen centre. Considering the lateral magnitude the maximum out-of-plane magnitude is $40 \%$ the skin thickness, again from the specimen edge to specimen centre. It is worth noting that the specimen measured geometric imperfection magnitude is large when compared to typical aerospace riveted panel tolerances, which are closer to $10 \%$ of the skin thickness. The reason for such a relatively large magnitude is the specimen's lack of support from surrounding panel structure and from lateral frames etc. The mechanical milling process undertaken to produce the skin pockets has undoubtedly had a significant influence on the form and magnitude of this geometric imperfection. In addition, the welding process will generate additional distortion due to the thermal and mechanical stresses developed in the weld region from the localised application of heat. To determine the level of specimen residual stress the third specimen, FSW-SSC-3, was used to experimentally measure specimen residual stresses at a number of key locations using the incremental hole-drilling method ${ }^{9,10}$. The residual stresses were measured with the specimen in its distorted state having been unclamped from the welding machine and section to its final test geometry. The measured specimen residual stresses relate to the welding and the machining processes as well as the skin sheet production rolling process. Unfortunately, the measured state of stress cannot be sub-divided and apportioned to the previously applied production processes as will be emphasised later.

Considering the specimen material properties, material compression test coupons were cut from the second specimen (FSW-SSC-2) and parent (unwelded) material properties were obtained. These were then used to generate parent material Ramberg-Osgood stress-strain relationships. In the weld region, due to the localised application of heat there will be a localised loss of mechanical properties. To determine the width of the weld HAZ a series of Vickers microhardness cross-sections of the specimen welds were preformed, again using FSW-SSC-2. Fig. 2 depicts a typical weld zone hardness map. Examining the hardness distribution one can see the variation and gradual transition between the thermo-mechanically affected zone, the heat affected zone and the unaffected zone (parent material). Within the strength analysis a single zone will represent this complex region ${ }^{11}$ and therefore analysis is required to assess the width of the degraded zone and the averaged level of degradation within the zone. Comparing the parent and local weld zone hardness data the width of the degraded zone was defined. Based on this width, material coupon tests were sectioned from the specimen (FSW-SSC-2) and tests preformed to determine the HAZ strength factors $\left(\mathrm{k}_{\mathrm{z}}\right)$ i.e. the reduction in material yield stresses $\left(\sigma_{0.1 \%}\right.$ and $\left.\sigma_{0.2 \%}\right)$ with reference to 
the parent material properties. With the determined HAZ yield stresses and the HAZ elastic modulus (unchanged from that of the parent material) Ramberg-Osgood stress-strain relationships were then generated for the HAZ materials.

The remaining specimen (FSW-SSC-1) was then marked and strain gauged in preparation for test. 47 $\mathrm{mm}(1.85$ ") depth Cerrobend (low melting point alloy) bases were cast on to the top and bottom ends of the specimen, producing a fully-clamped boundary condition at each end, Fig. 1. The ends were machined flat and parallel to ensure that a uniform compression load was applied. The specimen was then tested to failure using a $250 \mathrm{kN}$ displacement-controlled hydraulic testing machine. The test was carried out by applying the compression load monotonically at a rate of approximately $10 \mathrm{kN} / \mathrm{min}$ until specimen collapse. Skin and stiffener strain data (via strain gauges), specimen compressive end-shortening data (calibrated displacement transducers) and skin full-field deformation data (Digital Image Correlation) were recorded at set time intervals.

\section{B. Finite Element modelling methodology}

Using the Finite Element method and employing non-linear material and geometric analysis procedures, it is possible to model the initial skin buckling and post buckling failure behaviour of stiffened panels ${ }^{12,13}$ and to include welding process effects ${ }^{14}$. In order to represent the buckling failure modes of a stiffened panel the structure must be idealised as an assemblage of shell elements, with the skin and stiffener web and flanges represented as a series of inter-connected plates ${ }^{15}$. In addition, the skin and stiffener joint area must be appropriately represented, modelling the weld connection between the skin and stiffener flange and the contact conditions between the unconnected skin and stiffener flange ${ }^{14}$. Fig. 3 presents the Finite Element joint representation, in which the nodes in the skin and stiffener weld joint area are connected with rigid links and the contact conditions between the unwelded skin and stiffener flange are modelled with uni-axial gap elements.

To enable element selection a series of mesh convergence studies were undertaken. The buckling behaviour of uniformly compressed rectangular plates with geometries and boundary conditions designed to replicate those of the structure under investigation were carried out. Each analysis set was developed such that a theoretical buckling calculation could be performed. The performance of three ABAQUS elements were assessed based on convergence with corresponding theoretical behaviour with increasing mesh densities. Based on these analyses the first-order, doubly curved, 4-noded quadrilateral, small strain, thin shell element, S4R $5^{16}$ was selected. 
The loads and boundary conditions applied to the specimen models during the static strength analysis were designed to be as representative of the experimental test setup as possible, with the same loading and boundary conditions applied to all models, Fig. 3. A uniform axial displacement was applied to one end of the model with the axial displacement at the opposite end restrained. Out-of-plane displacements of the nodes within the areas that were cast in Cerrobend in the experimental test were also restrained.

For the validation of the simulation procedures the HAZ material stress-strain curves and the parent material stress-strain curves were incorporated into the finite element analysis models using the "classical metal plasticity' constitutive theory available within the ABAQUS material library ${ }^{16}$. For the validation of the simulation procedures the weld joint geometry, i.e. the lateral width of the physically joined skin and stiffener flange, was taken directly from the specimen measured joint geometry.

The introduction of an initial imperfection, either a stress free geometric imperfection, an initial stress state or combined initial stress state and geometric imperfection, eliminates bifurcation points from the non-linear structural solution path and allows the complete initial buckling, post-buckling and ultimate collapse simulation of the stiffened panel structure. Therefore each specimen structural simulation requires a two phased solution procedure; the first phase analysis starts with the perfect specimen geometry to which an initial imperfection is applied. The combined distorted and/or stressed state obtained from the first phase analysis is used as the initial condition for the second phase static strength analysis. This analysis starts with the imperfect model and a full non-linear material and geometric post buckling analysis is then performed using the incremental-iterative Newton-Raphson solution procedure.

Based on theory ${ }^{17}$ and clearly demonstrated in the literature ${ }^{18,19}$, the modelling of initial imperfections is of great importance when evaluating initial buckling behaviour. Three initial imperfection states are examined at this simulation validation phase to assess the significance of modelling initial specimen geometric and residual stress states:

a) The first imperfection considered is a stress free geometric imperfection based on the form and magnitude of the specimen measured geometric imperfections. In this case the Finite Element mesh nodes, representing the 'perfect' specimen geometry, are deflected into the form of the specimen measured geometric imperfection. This is the standard method of imperfection introduction for the collapse analysis of thin-walled structures. Typically, when the form and magnitude of the geometric imperfection is unknown, an eigenvalue analysis of the structure is undertaken and the fundamental eigenmode is used as the imperfection form, with a prescribed magnitude relating to the utilised manufacturing process. A superior method introduced by Hilburger et $\mathrm{al}^{20}$ applies a 'characteristic 
manufacturing imperfection signature', in which the applied analysis imperfection (form and magnitude) is statistically derived from the imperfection measurements of similar structures which have been produced by the same manufacturing process.

b) The second imperfection considered is a residual stress state based on the magnitude of the specimen measured residual stresses. This category of imperfection is analysed given the importance of initial stress with regards to buckling performance. As residual stress was only measured at a number of point locations, 12 in total, and those locations were restricted to the specimen flat skin (to avoid measurement distortions due to geometry and material property variation in the weld zone), the stress state was necessarily idealised based on theoretical welding residual stress patterns ${ }^{21}$. The assumed welding stress pattern idealised the longitudinal stresses into tensile stress blocks at the weld zones and equilibrating compressive stress blocks outside the weld zones. The stresses are idealised such that the skin and stiffener stresses do not vary in the longitudinal direction and remain constant through the skin, flange and web thicknesses. The measured transverse residual stresses were small in comparison with the longitudinal residual stresses and therefore were not modelled. A preliminary analysis to establish model global force and moment equilibrium was required. The equilibrium calculation generates a distorted structure, smaller than the globally measured distortion and a modified stress state at the specimen edges. It is worth noting also, that only the magnitude of the initial geometric imperfection changes with increased residual stress magnitude, the resultant geometric shape remains constant.

c) The third and final imperfection examined is a combination of the stress free geometric imperfection based on the form and magnitude of the specimen measured initial geometry and the specimen measured residual stresses. As before the introduction of the idealised residual stress state requires the establishing of model equilibrium, and this results in a slightly modified geometric imperfection state.

Fig. 4 presents the final state of stress and geometric imperfection for the above imperfection states, a) $-c)$. These states are used as the initial condition for the second phase static strength analysis as outlined above.

\section{Validation results}

Within this section the experimental data along with the baseline finite element predictions are presented to allow the assessment of the applied Finite Element simulation procedure and the three initial imperfection states. 


\section{Experimental results}

The experimental initial buckling and collapse loads for the validation specimen are presented in Table 2. Specimen initial skin buckling occurred at approximately $13 \%$ of the ultimate collapse load, at a stress equivalent to $42 \%$ that predicted by a simple plate buckling calculation, assuming all plate edges are simply supported and a plate width equal to the distance between stiffener weld centres. Specimen collapse involved failure of the central stiffener with a combined global stiffener flexure and local free flange and web buckling mode, Fig. 5a. Specimen weld joint integrity was maintained throughout initial skin buckling, post-buckling and ultimately overall specimen collapse, with the central stiffener weld failing shortly after the specimen maximum load was exceeded. Fig. 5a depicts the specimen initial skin buckling deformed shape, consisting of five approximately equal buckle half-waves along the length of the specimen right hand skin bay, with almost an equivalent asymmetric pattern in the specimen left hand skin bay. In the upper segment of the left hand skin bay however, the first two buckle half-waves have combined, buckling in the same direction. Fig. 6 presents the experimental load versus end-shortening curves illustrating the specimen pre- and post-buckling stiffness.

\section{Simulation results with the stress free geometric imperfection}

The FE simulation predicts the same combined global stiffener flexure and local stiffener free flange and web buckling mode as found experimentally, Fig. 5b. Examining the load versus end-shortening curves, Fig. 6 , the predicted specimen pre-buckling stiffness is marginally higher than the experimental stiffness with the post-buckling stiffness slightly lower. Generally there is good agreement between the simulation and the experimental collapse mode, Fig. 5b, with a very small difference in predicted and measured ultimate collapse load $(+0.6 \%)$, Table 2 . However, the predicted and measured specimen endshortening at ultimate load differ by $6.1 \%(0.26 \mathrm{~mm})$, resulting from the lower post-buckling stiffness predicted.

The predicted initial skin buckling mode is different than that found experimentally, with the simulation predicting the same five buckle half-waves along the length of the specimen, but with a symmetric pattern between the two skin bays. It is worth noting the predicted skin mode jump, with the specimen skin jumping at approximately $109 \mathrm{kN}$, Fig. 6, from the initial five symmetric half-waves to five asymmetric half-waves. Importantly, the predicted initial skin buckling load is significantly larger than that measured experimentally $(+41.9 \%)$, and this is likely to relate to the initial imperfection state modelled, given no initial residual stresses were represented. 


\section{Simulation results with the residual stress state imperfection}

Again Table 2 presents the simulation predicted buckling and collapse loads along with the experimental data. The simulation predicts the correct central stiffener failure mode, Fig. 5c. However, examining the load versus end-shortening curves, the predicted specimen post-buckling stiffness is lower than that found experimentally and the collapse load is over predicted by $4.1 \%$. Considering initial skin buckling, the simulation predicts a load some $48.5 \%$ smaller than the previous simulation but $27.0 \%$ below the experimental value. The predicted initial skin buckling mode is the same as that predicted by the previous simulation (five buckle half-waves along the length of the specimen, with a symmetric pattern between the two skin bays), Fig. 5c.

\section{Simulation results with the combined geometric and residual stress state imperfection}

Table 2 presents the predicted initial skin buckling and collapse loads for the simulation, Fig. $5 \mathrm{~d}$ the buckling modes and Fig. 6 the stiffness data. Again, the simulation predicts the experimental collapse mode and under predicts load by $0.6 \%$. The stiffness data, Fig. 6 , closely resembles the first simulation, i.e. with the stress free geometric imperfection. Examining the initial skin buckling behaviour, the simulation predicts five half-waves along the length of each skin bay, with the waves asymmetric between the bays. The predicted initial skin buckling load is $9.3 \%$ larger than the previous simulation and $19.5 \%$ lower than that found experimentally.

The preliminary validation simulations have demonstrated the appropriateness of the applied Finite Element idealisations and simulation procedures, given the closeness of simulation predictions and experimental initial buckling and failure behaviour. However, the results have also highlighted the sensitivity of initial skin buckling performance to the initial specimen geometric and residual stress states and the importance of modelling both. For the validation specimens, both the measured geometric and residual stress states relate to the machining and welding processes involved in there production. In this study we are primarily interested in understanding the influence of welding process effects on static strength performance. Therefore careful selection of the initial state is required for the following computational statistical studies. Clearly the mechanical milling process undertaken to produce the skin pockets in the validation specimens had a significant influence on the measured geometric imperfections and the measured residual stresses, and therefore a real influence on the specimen static strength performance. Consequently, in order to eliminate any potential interference or obscuring of analysis results, the following simulation studies will be preformed considering geometric imperfection due to welding induced residual stresses only. However, we will return to the results presented within this 
validation section when considering the welding effect simulation results, to consider the relative performance sensitivity of exclusively welding effects against those of combined milling and welding as measured and modelled here.

\section{Statistical Analysis of Welding Process Effects}

Having established the relative accuracy of the FE idealisation and simulation procedures it is now possible to use these methods to determine which of the welding process effects have the greatest influence on buckling performance. Based on previous experimental and analytical analysis four key welding process effects are to be investigated. Each welding effect is explained in the following subsections along with applied idealisations. The sub-sections also detail the range of welding effect magnitudes to be considered.

\section{A. Welding process effects}

\section{Weld joint width}

The weld joint width ( $\mathrm{w}_{\text {weld }}$ ) is the lateral width of the physically joined skin and stiffener flange material. The weld joint width is directly related to the weld tool pin diameter. For the validation specimens the width of the weld joint is approximately twice the thickness of the welded through flange $\left(\mathrm{t}_{\mathrm{af}}\right)$. Considering experimental weld measurements a selected range of upper and lower bounds of $3 \times t_{a f}$ and 1 $\mathrm{X} \mathrm{t}_{\mathrm{af}}$ are considered in the computational studies.

\section{Strength of material within the weld Heat Affected Zone}

The factor $\mathrm{k}_{\mathrm{z}}$ relates the strength of heat affected material to the parent material, $\mathrm{k}_{\mathrm{z}}$ being equal to the ratio of HAZ material proof stress to the parent material proof stress. The material within the HAZ generally has lower strength than the parent material. Again based on experimental weld measurements, a range of $65 \%$ to $95 \%$ of the parent material properties are considered for $\mathrm{k}_{\mathrm{z}}$ in the computational studies.

\section{Heat Affected Zone width}

The Heat Affected Zone width (z) is the distance the HAZ extends from the weld centre line and is primarily influenced by the welding parameters and work piece material. Data from weld cross-section hardness tests have been used to determine the range of upper $6 \mathrm{xt} \mathrm{t}_{\mathrm{af}}$ and lower $3 \times \mathrm{t}_{\mathrm{af}}$ for the computational studies.

\section{Magnitude of residual stresses}

The induced welding residual stresses $\left(\sigma_{\text {res }}\right)$, due to the welding heating and softening cycle, are typically defined in relation to the material proof stress. Given the loading direction within the present study, the 
magnitude of the longitudinal compressive stresses are potentially of greater importance than the magnitude of the tensile stresses. However, welding process data is normally in the form of tensile residual stress magnitude and width. Therefore, the magnitude of residual stresses is presented in terms of tensile residual stress. However, the tensile residual stresses are directly related to the compressive residual stresses given the requirement for residual stress equilibrium. Considering experimental weld measurements and welding process simulations, the studies consider values of longitudinal tensile residual stress in the weld zone, ranging from $20 \%$ to $50 \%$ of the parent material's proportional limit. As in the preliminary validation simulations the transverse residual stresses were considered small in comparison with the longitudinal residual stresses and therefore not modelled.

Table 3 summaries the welding process effects to be studied and the range of magnitudes to be considered. Although the material type and welding method have the greatest influence on the above welding process effects, advanced methods such as fabrication mechanical tensioning and work-piece post-weld heat treatment offer the potential to control induced process effects. With such developments, variations in welding process effects are possible with a single welding method and work-piece material.

\section{B. Preliminary DOE study}

To examine the welding effects outlined in Table 3 using a full factorial analysis and considering each welding effect at only four separate magnitudes would require a total of 256 analysis simulations. Given this potential cost a fractional factorial experiment design method, Taguchi, is employed to govern the analysis simulations, estimate the relative contributions of the individual welding process effects on performance and investigate interactions between welding process effects.

In the applied DOE method all input factors, welding process effects, are treated as discrete, being examined at only two levels, one value representing a "large" or "high" magnitude of the particular welding process effect and the other value representing a "small" or "low" magnitude of the particular welding process effect. A special set of orthogonal arrays are used to prescribe the required simulations and the level of each welding process effect in each simulation. Once the orthogonal array has been determined, simulations are carried out to predict the specimen initial skin buckling and collapse performance. Based on the simulation results (initial skin buckling and collapse loads) an 'Analysis of Means' is carried out to identify the dominant factors influencing the loads. Again based on the same simulation results an 'Analysis of Variance' is undertaken to determine the relative contributions of each factor to the predicted loads. Using the Taguchi method in the present case, only 8 analysis simulations are required to identify the dominant factors and their potential interactions, Table 4. 


\section{DOE Results}

For the 8 simulations the maximum difference in predicted specimen initial skin buckling load was $59.4 \%(12.9 \mathrm{kN})$, whereas the maximum difference in predicted specimen collapse load was $7.0 \%(12.6$ $\mathrm{kN}$ ). All 8 simulations first predict initial skin buckling and then specimen central stiffener failure with a combined global stiffener flexure and local free flange and web buckling mode.

Using the predicted initial skin buckling and collapse failure loads from the 8 Finite Element simulations, an "Analysis of Means" was carried out, enabling the four individual welding process effects to be ranked in order of influence on both initial skin buckling and collapse failure loads, Table 5. For the analysed range of effect magnitudes, residual stress has the greatest influence on the initial skin buckling performance, and weld joint width has the greatest influence on collapse performance. For initial skin buckling there is no interaction between weld joint width and HAZ material strength and between the HAZ width and the HAZ material strength. Interactions for collapse are slight in the studied range between weld joint width and HAZ material strength and between the HAZ width and the HAZ material strength.

An "Analysis of Variance" was then carried out to identify the relative significance of the individual factors and their interactions. Examining the results for initial skin buckling, Table 6, the magnitude of welding induced residual stress is again identified as the dominant welding process effect, with an individual contribution of approximately $99 \%$. Considering collapse, weld joint width has the most significant influence followed by the magnitude of initial residual stress and HAZ material strength.

It is worth noting that these initial results identifying the dominant welding process effect(s) and their level of influence on static strength are not fully generic, and are influenced by the range of effect magnitudes analysed. For this reason and to determine the sensitivity of the relationships, parametric studies covering the range of effect magnitudes outlined in Table 3 are now considered.

\section{Parametric studies}

Having identified the two greatest welding process effects as the initial residual stress and the weld joint width, the parametric studies will concentrate on these process effects. For the parametric study the magnitude of the welding induced residual stress is varied in 5\% steps from $15 \%$ to $55 \%$ with the weld joint width considered at 3 discrete levels $\left(1 \times t_{a f}, 2 \times t_{a f}\right.$ and $\left.3 \times t_{a f}\right)$. The HAZ width and HAZ material strength are held constant throughout the studies at $4.5 \times \mathrm{t}_{\mathrm{af}}$ and $80 \%$ respectively.

\section{A. Specimen initial skin buckling performance}


The parametric results for specimen initial skin buckling performance are presented in Fig. 7. The figure also presents the maximum out-of-plane magnitude of the induced geometric imperfection due to the applied residual stress state. Considering Fig. 7, it can be seen that the buckling load decreases continuously with higher magnitudes of initial residual stress and the associated resultant geometric imperfections. This agrees with theory, which emphasises the sensitivity of plate buckling to initial stress states and initial geometric imperfections. The reduction in performance is approximately linear in the examined range with the reduction approximately at a rate of $0.42 \mathrm{kN}$ per $1 \%$ increase in magnitude of the tensile residual stress. Over the total range of magnitudes considered (residual stress and weld joint width) there is a total decrease in specimen initial skin buckling performance of $72 \%(17.2 \mathrm{kN})$.

Comparing this with the validation analysis work which featured both welding and milling initial geometric imperfections and residual stresses - the variation in initial skin buckling performance between simulations with an initial residual stress state but with and without an initial geometric imperfection was only $1.4 \mathrm{kN}(8.2 \%)$. This suggests that the introduction of welding induced residual stresses may have a greater influence on initial skin buckling performance than geometric imperfections introduced due to milling of skin pockets.

Considering the influence of weld joint width, Fig. 7 confirms the DOE finding, that the effect of weld joint width is insignificant in relation to residual stress magnitude. Examining in detail the change in predicted performance with variation in weld joint widths and analysing a residual stress magnitude that produces the greatest difference in prediction (a magnitude of the tensile residual stress equal to $40 \%$ ), the performance values differ by only $1.4 \mathrm{kN}\left(1 \times \mathrm{t}_{\mathrm{af}}-13.0 \mathrm{kN}, 3 \times \mathrm{t}_{\mathrm{af}}-14.4 \mathrm{kN}\right)$.

Considering the scatter in the predicted initial skin buckling predictions it is worth noting the applied method of initial buckling definition. In the present study, the average strain method is used both in the experimental and computational analysis, therefore allowing comparison of the results. The method plots compression load versus mid-plane strain and buckling is defined to have occurred at the inflection point. The strain data used for each experimental and computational calculation is taken at the same locationthe centre of the specimen skin plate. The method therefore only considers a single point on the plate and, considering the non-localised behaviour of buckling, the analysis results are dependent on the measurement location and the initial buckling wave formation.

In summary, the initial skin buckling parametric results have again clearly demonstrated that the modelling of initial stress and geometric conditions is of great importance when evaluating initial skin buckling. The studied range of residual stresses relates to the measured magnitude of specimen stresses, 
though the FE modelled stress distribution is highly idealised. This is therefore an area potentially requiring further investigation.

\section{B. Specimen collapse performance}

Results for collapse performance with weld joint width set at $1 \mathrm{xt}_{\mathrm{af}}$ are presented in Fig. 8. There appears to be a general reduction of performance with increasing residual stress magnitude. The data suggests that there may be two regions, a relatively linear region up to $30 \%$ (magnitude of the tensile residual stress) with a low sensitivity (exhibiting a reduction of approximately $0.07 \mathrm{kN}$ per $1 \%$ increase in residual stress magnitude) and a non-linear region above $30 \%$, which appears less orderly.

Examining the predicted modes in Zone One (below 30\%) a consistent initial skin buckling mode is predicted with five buckle half-waves along each specimen skin section, with the pattern asymmetric about the specimen central stiffener. As with initial skin buckling, a consistent collapse mode is predicted in Zone One with the specimen central stiffener failing in a combined global stiffener flexure and local free flange and web buckling mode. As with the validation experimental failure mode, this occurs with three, approximately equal, half-waves along the stiffener length.

In Zone Two (above 30\%) predicted initial skin buckling modes vary with residual stress magnitude. For residual stress magnitudes of $35 \%$ and $45 \%$ a specimen symmetric five buckle half-wave pattern is predicted. With $40 \%$ and $55 \%$ a specimen asymmetric four buckle half-wave pattern is predicted, the inverse of which is predicted for a residual stress magnitude of 50\%. Accompanying these variations in predicted initial skin buckling modes are varying collapse modes. All models predict the same specimen central stiffener failure in a combined global stiffener flexure and local free flange and web buckling mode; however, the number and size of half-waves along the stiffener length varies. With a residual stress magnitude of $35 \%$ the predicted final failure mode is similar to that found in Zone One. At $40 \%$ and $50 \%$ the prediction is for three half-waves along the stiffener of unequal length. At $45 \%$ and $55 \%$ the prediction is for two half-waves of equal length along the stiffener. These variations in the final specimen collapse modes emerge in Fig. 8 as variations in collapse load.

Examining the results for collapse performance with weld joint width set at $2 \times t_{a f}$ and $3 \times t_{a f}$ produce the same two zones, below $30 \%$, the performance decreases slowly with increasing magnitudes of residual stress, above $30 \%$, the relationship between performance and residual stress magnitude is nonlinear. Again, as with the results for weld joint width $1 \mathrm{xt}_{\mathrm{af}}$, this behaviour can be traced back to varying buckling collapse modes. 
Applying a linear trend line to the results in Zone One, it is possible to examine the influence of weld joint width on collapse performance. Table 7, presents the effective slope and centre of the fitted trend lines. On examining the data presented it is clear that the collapse performance is relatively insensitive, within Zone One, to both the weld joint width and the residual stress magnitude. Examining the total range of effect magnitudes (residual stress and weld joint width) there is a total decrease in specimen collapse performance of $7 \%(12.1 \mathrm{kN})$. The variation in load level is approximately equal to the variation found for initial buckling performance. Given the relative magnitudes at which initial and collapse buckling occur, initial buckling performance is therefore influenced to a greater extent than ultimate collapse performance.

In summary, the collapse performance parametric results indicate that with low magnitudes of initial residual stress the performance in terms of collapse mode and load are orderly. At higher magnitudes of initial residual stress the form of the initial skin buckling mode varies, influencing the collapse mode of the structure and therefore the collapse load. The experimentally measured residual stresses for the validation specimens are in the boundary region between the 'orderly' and 'disorderly' behaviour ( $20 \%$ to $40 \%$ of the parent material's proportional limit). However, the variation in collapse load level is relatively small, $7 \%$ for the total range of residual stress levels examined ( $15 \%$ to $55 \%$ of the parent material's proportional limit). Given this and reviewing the validation analysis work which featured both welding and milling initial geometric imperfections and residual stresses - the variation in collapse performance between simulations with an initial residual stress state but with and without an initial geometric imperfection was $8.6 \mathrm{kN}(5.2 \%)$. This suggests that the introduction of welding induced residual stresses may have a smaller influence on collapse performance than geometric imperfections introduced due to milling of skin pockets. However, it is important to note that the specimen measured geometric imperfection magnitude is approximately $120 \%$ of the skin thickness whereas typical aerospace riveted panel tolerances are closer to $10 \%$ of the skin thickness.

\section{Conclusions}

Welding can introduce undesirable residual stresses and distortions in fabricated components, as well as localised loss of mechanical properties at weld joints. The aim of the research presented herein is the determination and characterisation of the key friction stir welding process effects on multi stiffener panels static strength performance. Four welding process effects were investigated, i) the weld joint width, ii) the width of the weld Heat Affected Zone, iii) the strength of material within the weld Heat Affected Zone and iv) the magnitude of residual stresses induced by the welding process. Utilising experimentally 
validated Finite Element methods, it is demonstrated that for the examined multi stiffener panels, initial skin buckling is predominantly influenced by the magnitude of welding induced residual stresses and associated geometric distortions. The results of both initial DOE analysis and detailed parametric analyses indicate that the ultimate collapse performance is less sensitive to the applied process effects and process effect magnitudes than initial buckling. Additionally, the preliminary validation simulation work has demonstrated the appropriateness of the applied FE idealisations and simulation procedures and highlighted the sensitivity of initial skin buckling performance to the initial specimen geometric and residual stress states. It is worth noting that the modelled residual stress distributions herein have been idealised and given the potential influence of initial stress states future work is required to study higher fidelity residual stress idealisations. It is intended to extend the current analysis and validation work to larger welded panels with both longitudinal and lateral stiffeners. For these studies the loading conditions will also be increased in complexity to consider combined shear and compression loading.

\section{Acknowledgments}

The authors wish to thank InvestNI (Grant \# CoE 32) for their financial assistance, as well as Gary Moore and Ken Poston for their technical support (Bombardier Aerospace Belfast).

\section{References}

1. Zink, W., "Laser beam welding for aircraft structures," Aeromat 2000, Daimler Chrysler Aerospace Airbus, Bremen, 2000.

2. Christner, B., McCoury, J., "Development and Testing of Friction Stir Welding (FSW) as a Joining Method for Primary Aircraft Structure," 4th International FSW Symposium, Park City, Utah, May $14-16,2003$.

3. Gibson, A., and Sterling, S., "A design and test programme involving welded sheet-stringer compression panels," ICAS 1998, Melbourne, Australia, August 1998, ICAS-98-7.7.4.

4. Dracup, B. J., and Arbegast, W. J., "Friction stir welding as a rivet replacement technology," Proceedings of the 1999 SAE Aerospace Automated Fastening Conference \& Exposition, Memphis, October 5-7, 1999.

5. Hoffman, E. K., Hafley, R. A., Wagner, J. A., Jegley, D. C., Pecquet, R. W., Blum, C. M., and Arbegast, W. J., "Compression Buckling Behaviour of Large-Scale Friction Stir Welded and Riveted 2090-T83 Al-Li Alloy Skin-Stiffener Panels,” NASA, August 2002, NASA/TM-2002-211770. 
6. Murphy, A., Lynch, F., Price, M., and Gibson., A., "Modified stiffened panel analysis methods for laser beam and friction stir welded aircraft panels," Journal of Aerospace Engineering, Vol. 220, G4, 2006, pp. 267, 278.

7. Murphy, A., Price, M., Curran, R., and Wang, P., "The Integration of Strength and Process Modeling of Friction-Stir-Welded Fuselage Panels,” AIAA Journal of Aerospace Computing, Information, and Communication, Vol. 3, April 2006, pp. 159, 176.

8. Rhodes, J., and Walker, A. C., Developments in thin-walled structures, Applied science publisher, London, 1982, Chapter 4.

9. Schajer, G. S., "Applications of Finite Element Calculations to Residual Stress Measurements", Journal Engineering Materials and Technology, Trans ASME 103, April 1981, pp. 157-163.

10. Schajer, G. S., "Measurement of Non-Uniform Residual Stresses Using the Hole Drilling Method", Journal Engineering Materials and Technology, 110 (4), 1988, Part I: pp.338-343, Part II: pp.3445349.

11. British Standard 8118. "Structural use of aluminium, Part 1: Code of practice for design," British Standards Institution, London, 1991 (ISBN 058019209 1).

12. Lynch, C., Murphy, A., Price, M., and Gibson, A., "The computational post buckling analysis of fuselage stiffened panels loaded in compression," Thin-Walled Structures, Vol. 42, No. 10, 2004, pp. $1445,1464$.

13. Murphy, A., Price, M., Lynch, C., and Gibson, A., "The computational post buckling analysis of fuselage stiffened panels loaded in shear," Thin-Walled Structures, Vol. 43, No. 9, 2005, pp. 1455, 1474.

14. Murphy, A., Lynch, F., Price, M., and Wang, P., "The Static Strength Analysis of Friction Stir Welded Stiffened Panels for Primary Fuselage Structure,” ICAS 2004, Yokohama, August 2004, ICAS-2004-5.6.3.

15. Domb, M. M., Elliott, W. G., Leigh, B. R., "Modeling of Stiffener Crippling Phenomena using Finite Element Analysis," Canadian Aeronautics and Space Journal, Vol. 44, No. 4, 1998, pp. $256,262$.

16. Anonymous, “ABAQUS / Standard user's manual”, Version 6.1, Hibbitt, Karlsson and Sorenson, 2000 .

17. Bulson, P.S., The stability of flat plates. 1st ed. London: Chatto; 1970.

18. Hu, S.Z., Jiang, L., "A finite element simulation of the test procedure of stiffened panels," Marine Structures, Vol. 11, 1998, pp. 75,99. 
19. Baker, D.J., Kassapoglou, C., "Post buckled composite panels for helicopter fuselages: Design, analysis, fabrication and testing," Presented at the American Helicopter Society, Hampton roads chapter, structures specialists meeting, Williamsburg VA US, October 2001.

20. Hilburger, M.W., Nemeth, M.P., and Starnes, J.H., "Shell Buckling Design Criteria Based on Manufacturing Imperfection Signatures”, AIAA Journal, 44, (3), March 2006.

21. Paik, J.K., Thayamballi, A.K., "Ultimate limit state design of steel plated structures," John Wiley \& Sons, 2003. 


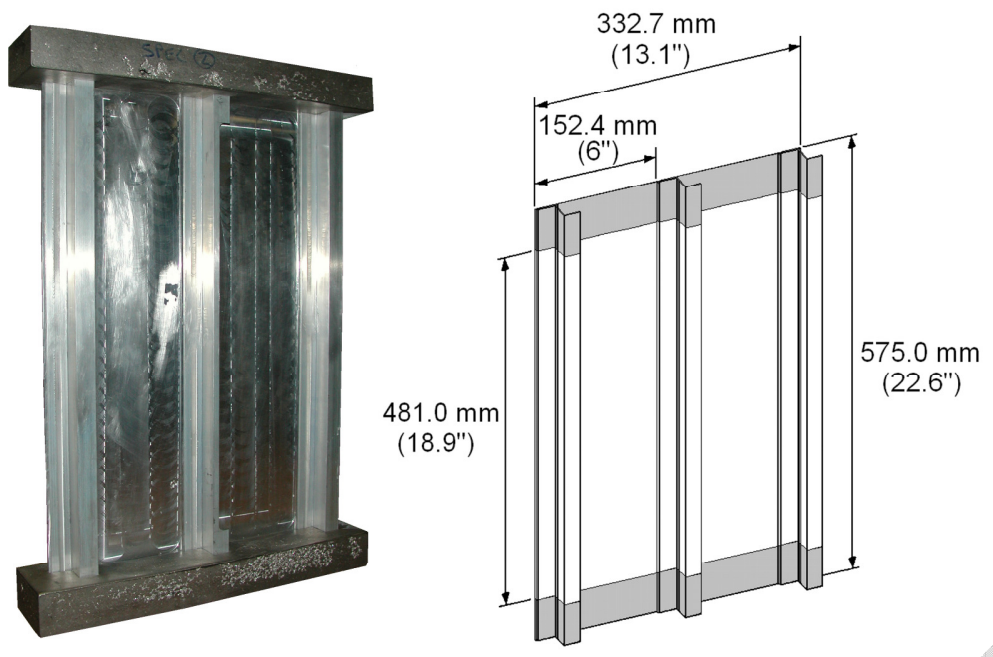

Figure 1. Sub-Component specimen configuration. 


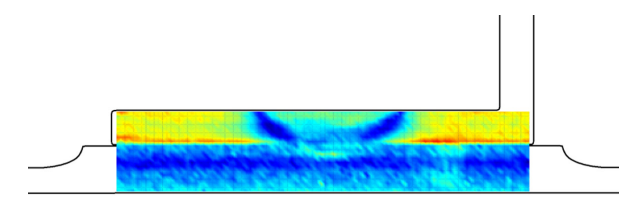

Figure 2. Vickers microhardness cross-section of a weld joint. 


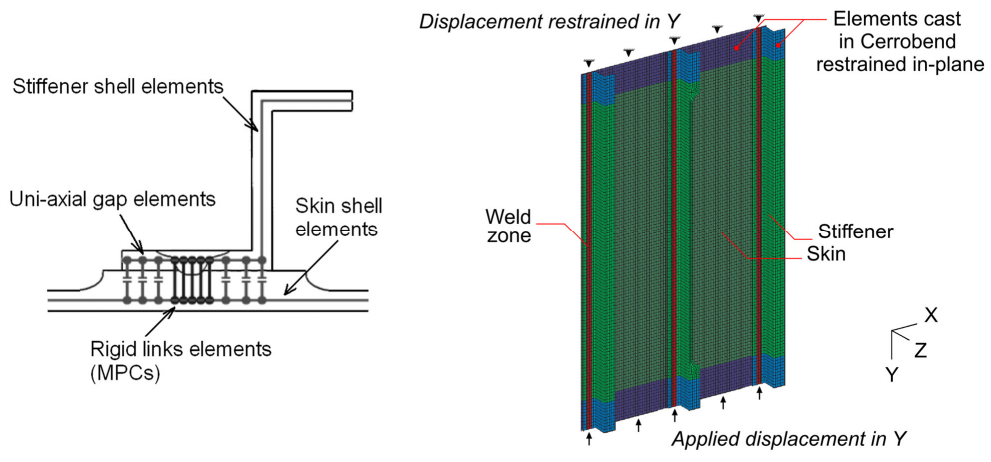

Figure 3. FE model lap weld joint idealization and applied loading and boundary conditions. 

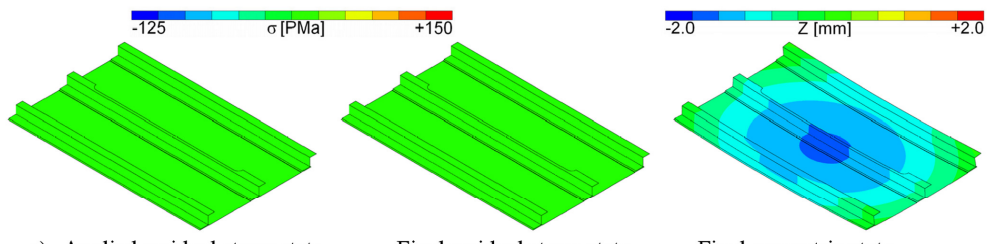

a) Applied residual stress state Final residual stress state Final geometric state
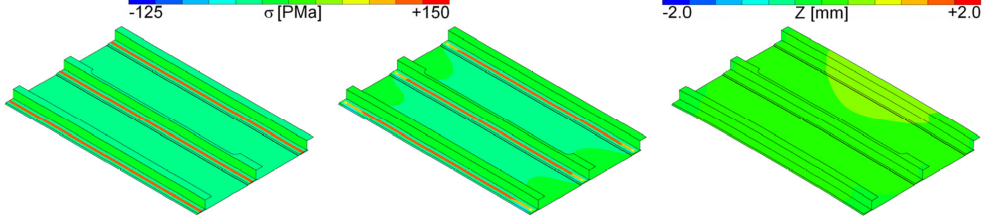

b) Applied residual stress state

Final residual stress state

Final geometric state

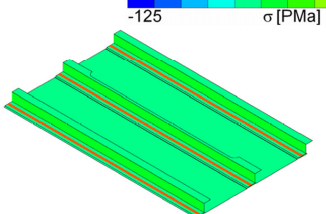
$+150$ $\begin{array}{lll}-2.0 & \mathrm{Z}[\mathrm{mm}] & +2.0\end{array}$

c) Applied residual stress state

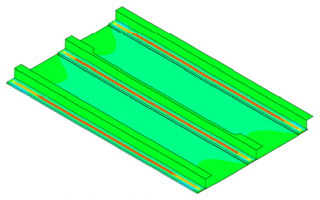

Final residual stress state

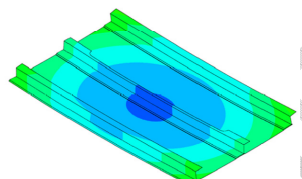

Final geometric state

Figure 4. Initial imperfections. 


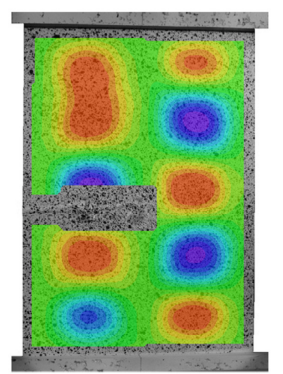

a) Initial skin buckling (skin side view)

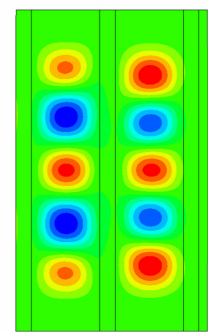

b) Initial skin buckling (skin side view)

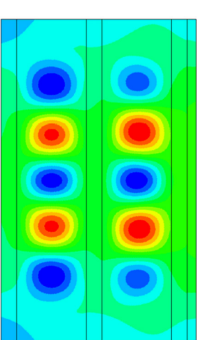

c) Initial skin buckling (skin side view)

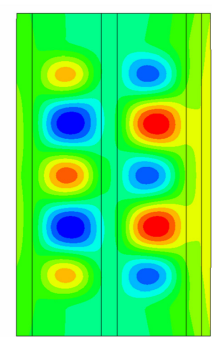

d) Initial skin buckling (skin side view)

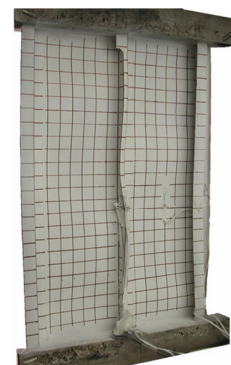

Ultimate collapse (stiffener side view)

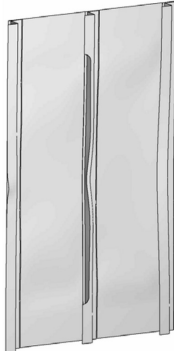

Ultimate collapse (stiffener side view)

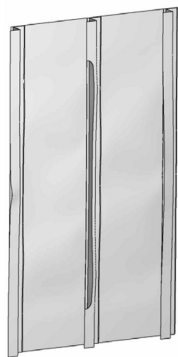

Ultimate collapse (stiffener side view)

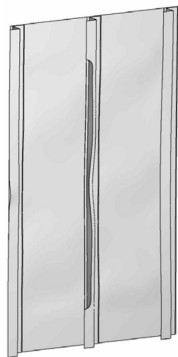

Ultimate collapse (stiffener side view)

Figure 5. Specimen mode shapes for the validation analysis. 


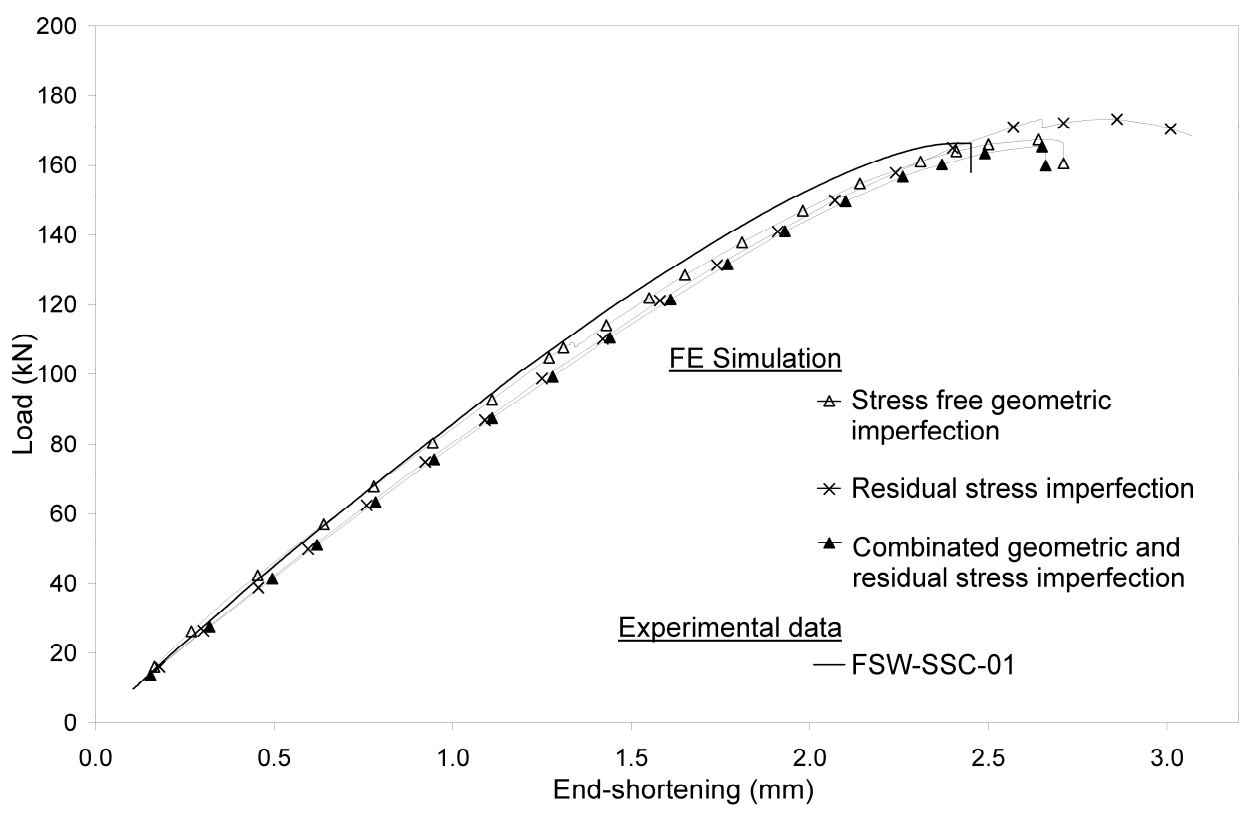

Figure 6. Load versus end-shortening curves for the validation analysis. 


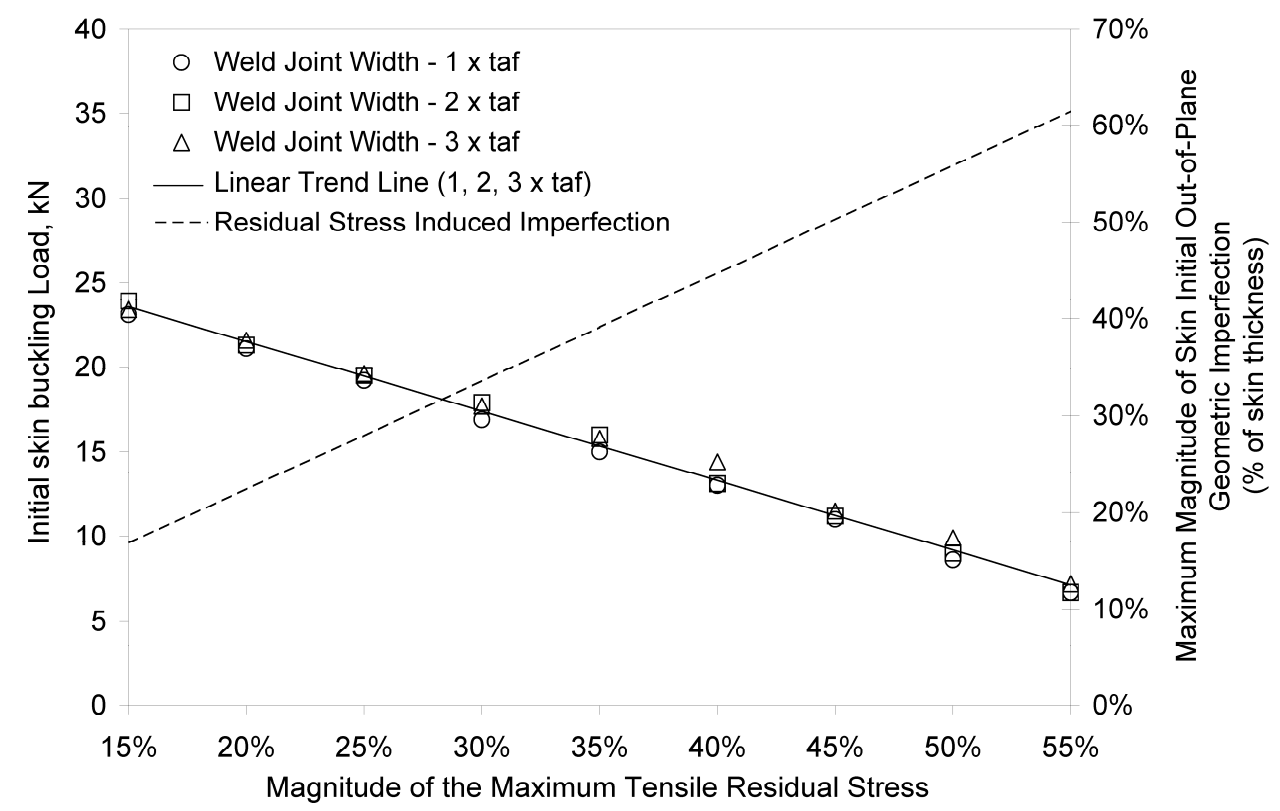

Figure 7. Parametric results - influence of residual stress magnitude on specimen initial skin buckling load. 


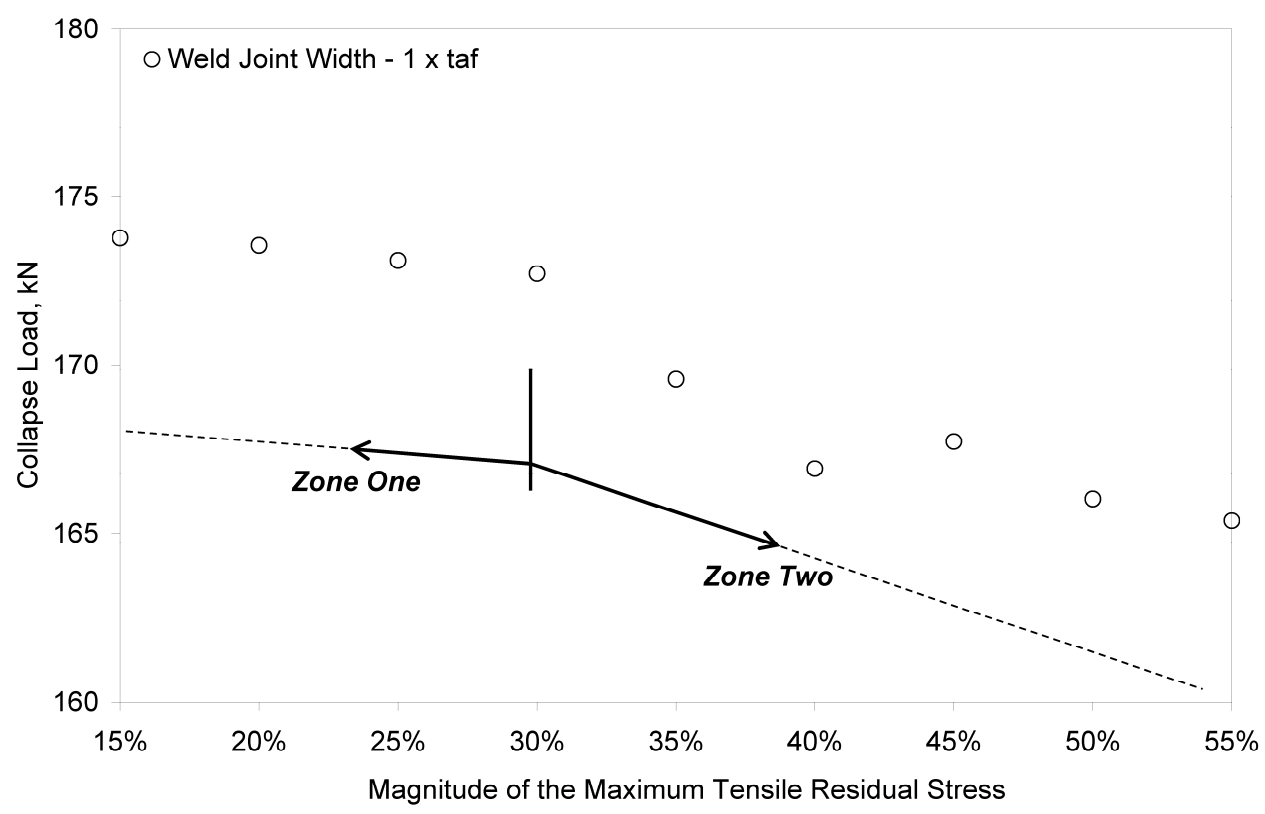

Figure 8. Parametric results - influence of residual stress magnitude on specimen collapse load (weld joint width equal to $\left.1 \times t_{a f}\right)$. 
Table 1.

Validation specimen stiffeners geometry.

Single frame bay specimen

\begin{tabular}{|c|c|c|}
\hline & $\begin{array}{c}\text { Edge stiffeners } \\
\text { [welded] } \\
(\mathrm{mm})\end{array}$ & $\begin{array}{c}\text { Central stiffeners } \\
\text { [welded] } \\
(\mathrm{mm})\end{array}$ \\
\hline $\mathbf{h}_{\mathbf{s}}$ & 25.4 & 25.4 \\
\hline $\mathbf{b}_{\mathrm{ff}}$ & 20.3 & 7.3 \\
\hline$b_{\text {af }}$ & 22.9 & 22.9 \\
\hline$t_{w}$ & 1.6 & 1.6 \\
\hline$t_{f f}$ & 1.6 & 1.6 \\
\hline$t_{a f}$ & 1.6 & 1.6 \\
\hline$t_{\text {skin }}$ & \multicolumn{2}{|c|}{1.2} \\
\hline
\end{tabular}

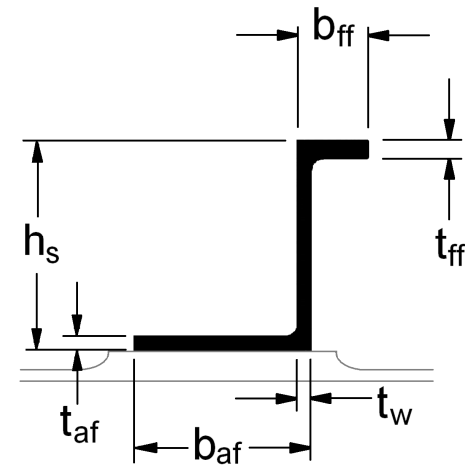


Table 2.

Experimental and predicted validation specimen initial skin buckling and collapse loads.

\begin{tabular}{lcc}
\multicolumn{1}{c}{ Test specimen } & $\begin{array}{c}\text { Initial skin } \\
\text { buckling load } \\
(\mathbf{k N})\end{array}$ & $\begin{array}{c}\text { Specimen } \\
\text { collapse load } \\
(\mathbf{k N})\end{array}$ \\
\hline FSW-SSC-1 & 21.5 & 166.4 \\
\hline $\begin{array}{l}\text { FE Predictions } \\
\text { a) Stress free geometric imperfection }\end{array}$ & $30.5(+41.9 \%)^{1}$ & $167.4(+0.6 \%)^{1}$ \\
$\begin{array}{l}\text { b) Residual stress state imperfection } \\
\text { c) Combined geometric and residual } \\
\text { stress state imperfection }\end{array}$ & $15.7(-27.0 \%)^{1}$ & $173.2(+4.1 \%)^{1}$ \\
\hline${ }^{\prime}-$ Percentage different based on experimental data. & $17.3(-19.5 \%)^{1}$ & $165.4(-0.6 \%)^{1}$ \\
\hline
\end{tabular}


Table 3.

Welding process effect variables and magnitude ranges.

Variable Range

\begin{tabular}{clccc} 
Factor & Analysis Variable & & Lower & Upper \\
\hline A & Weld joint width & $(\mathrm{mm})$ & $1 \mathrm{t}_{\mathrm{af}}$ & $3 \mathrm{t}_{\mathrm{af}}$ \\
B & HAZ material strength & $\left(\%{ }^{1}\right)$ & 65 & 95 \\
C & HAZ width & $(\mathrm{mm})$ & $3 \mathrm{t}_{\mathrm{af}}$ & $6 \mathrm{t}_{\mathrm{af}}$ \\
D & Residual stress & $\left(\%{ }^{2}\right)$ & 20 & 50 \\
${ }^{1}-$ Percentage of parent material strength. \\
${ }^{2}-\begin{array}{l}\text { Percentage of proportional limit of parent material set as } \\
\text { magnitude of welding induced tensile residual stress. }\end{array}$ \\
\hline
\end{tabular}


Table 4.

Welding process effect orthogonal array.

\begin{tabular}{|c|c|c|c|c|c|c|}
\hline $\begin{array}{c}\text { Finite Element } \\
\text { simulation } \\
\text { number }\end{array}$ & $\begin{array}{c}\text { Weld joint } \\
\text { width } \\
\text { (mm) }\end{array}$ & $\begin{array}{c}\text { HAZ width } \\
\text { (mm) }\end{array}$ & $\begin{array}{c}\text { Interaction } \\
\begin{array}{c}\text { Weld joint } \\
\text { width } \\
\text { X }\end{array} \\
\text { HAZ width }\end{array}$ & $\begin{array}{c}\text { HAZ material } \\
\text { strength } \\
\left(\%^{1}\right)\end{array}$ & $\begin{array}{c}\text { Residual } \\
\text { stress } \\
\left(\%^{2}\right)\end{array}$ & $\begin{array}{c}\frac{\text { Interaction }}{\text { HAZ material }} \\
\text { strength } \\
\text { X } \\
\text { HAZ width }\end{array}$ \\
\hline 1 & $1 \mathrm{t}_{\mathrm{af}}$ & $3 t_{a f}$ & 1 & 65 & 20 & 1 \\
\hline 2 & $1 t_{a f}$ & $3 t_{a f}$ & 1 & 95 & 50 & 2 \\
\hline 3 & $1 \mathrm{t}_{\mathrm{af}}$ & $6 \mathrm{t}_{\mathrm{af}}$ & 2 & 65 & 20 & 2 \\
\hline 4 & $1 \mathrm{t}_{\mathrm{af}}$ & $6 \mathrm{t}_{\mathrm{af}}$ & 2 & 95 & 50 & 1 \\
\hline 5 & $3 t_{a f}$ & $3 t_{a f}$ & 2 & 65 & 50 & 1 \\
\hline 6 & $3 t_{a f}$ & $3 t_{a f}$ & 2 & 95 & 20 & 2 \\
\hline 7 & $3 t_{a f}$ & $6 \mathrm{t}_{\mathrm{af}}$ & 1 & 65 & 50 & 2 \\
\hline 8 & $3 t_{a f}$ & $6 \mathrm{t}_{\mathrm{af}}$ & 1 & 95 & 20 & 1 \\
\hline
\end{tabular}


Table 5.

Analysis of Means - ranked order of influence.

\begin{tabular}{ccc}
$\begin{array}{c}\text { Factor } \\
\text { Ranking }\end{array}$ & $\begin{array}{c}\text { Local skin buckling } \\
\text { load }\end{array}$ & $\begin{array}{c}\text { Specimen collapse } \\
\text { load }\end{array}$ \\
$\mathbf{1}$ & Residual stress & Weld joint width \\
$\mathbf{2}$ & Weld joint width & Residual stress \\
$\mathbf{3}$ & HAZ material & $\begin{array}{c}\text { HAZ material } \\
\text { strength }\end{array}$ \\
$\mathbf{4}$ & HAZ width & HAZ width \\
\hline
\end{tabular}


Table 6.

Analysis of Variance - relative contributions.

\begin{tabular}{lcc}
\hline & $\begin{array}{c}\text { Local skin buckling } \\
\text { load } \\
\text { (\% contribution) }\end{array}$ & $\begin{array}{c}\text { Specimen collapse } \\
\text { load } \\
\text { (\% contribution) }\end{array}$ \\
\hline Weld joint width & $0.6 \%$ & $67.4 \%$ \\
HAZ width & $0.0 \%$ & $0.4 \%$ \\
HAZ material strength & $0.1 \%$ & $11.1 \%$ \\
Residual stress & $99.3 \%$ & $17.2 \%$ \\
Interaction [Weld joint width x HAZ material strength] & $0.0 \%$ & $1.5 \%$ \\
Interaction [HAZ width x HAZ material strength] & $0.0 \%$ & $0.9 \%$ \\
Error & $0.0 \%$ & $1.5 \%$ \\
\hline
\end{tabular}


Table 7.

Zone One - trend data.

\begin{tabular}{ccc}
\hline $\begin{array}{c}\text { Weld joint } \\
\text { width }\end{array}$ & $\begin{array}{c}\text { Reduction in collapse load with an increase } \\
\text { in residual stress magnitude from 15\% to } \\
\mathbf{3 0 \%} \text {, based on data fit }\end{array}$ & $\begin{array}{c}\text { Specimen collapse load at a residual stress } \\
\text { magnitude of 22.5\%, based on data fit }\end{array}$ \\
\hline $1 \times \mathrm{t}_{\mathrm{af}}$ & $1.1 \mathrm{kN}$ & $173.3 \mathrm{kN}$ \\
$2 \times \mathrm{t}_{\mathrm{af}}$ & $0.9 \mathrm{kN}$ & $176.0 \mathrm{kN}$ \\
$3 \mathrm{xt}_{\mathrm{af}}$ & $1.2 \mathrm{kN}$ & $176.8 \mathrm{kN}$
\end{tabular}

